\title{
AVALIAÇÁO dO POTENCIAL AGRONÔMICO DE INTRODUÇÕES DE AMENDOIM COM VISTAS AO MELHORAMENTO GENETICO
}

\author{
IGNACIO JOSÉ DE GODOY $(2,7)$, SÉRGIO ALMEIDA DE MORAES (3.7), \\ ANTON \\ ALVES PEREIRA (5) e RENATO FERRAZ DE ARRUDA VEIGA $(6,7)$
}

\begin{abstract}
RESUMO
Visando à escolha de parentais para o programa de melhoramento de amendoim ( Arachis hypogaea L.), avaliaram-se, quanto à capacidade produtiva, vinte e trés introduçőes da coleçăo de germoplasma do Instituto Agronómico e os cultivares Tatul e Tatu, este último usado como controle. Os experimentos foram realizados durante o cultivo das águas de 1985/86 e 1986/87, no Centro Experimental, de Campinas e na Estação Experimental de Pindorama, e de 1985/86, na Estaçăo Experimental de Ribeirão Preto. Analisaram-se sementes obtidas desses ensaios, à exceçăo do de Pinđorama, 1986/87, quanto ao teor de oleo, e, ainda: as reaçסes de cada tratamento a quatro das principais manchas foliares do amendoim, hábito de crescimento, ciclo e caracterlsticas de vagens e sementes. Destacaram-se, na média dos experimentos, com produtividade significativamente superior ao controle, as linhagens $5475,5207,5249$ e H-69 e o cultivar Tatul. As meIhores produçōes foram observadas nas linhagens 5475 (ereta, precoce, do grupo Valéncia) e 5207 (tipo arbustivo, ciclo longo, do grupo Virglnia), cujas médias foram em $30 \%$ superiores à do cultivar Tatu. Apenas as linhagens 269 e 70 apresentaram teores de bleo superiores ao controle em $3 \%$. A 5207 e 5249, de born desempenho produtivo, tiveram teores de bleo significativamente inferiores ao controle. Algumas das introduçбes mostraram trazer, no genótipo, além do potencial de produçăo, algum nivel de resistência a doenças, destacando-se a linhagem 5207 , como moderadamente suscetivel à pinta-preta e à verrugose e moderadamente resistente à mancha-barrenta, e a linhagem 5475 , como moderadamente suscetfvel à pinta-preta, moderadamente resistente à verrugose e resistente à mancha-barrenta e à ferrugem. Pela produtividade e nlvel de resistência à doença, ambas estăo sendo incluldas em cruzamentos com linhagens de bom padrăo comercial e qualidade de vagens, por suas limitaçס̋es para essas caracteristicas.
\end{abstract}

(1) Parcialmente financiado por recursos de convênio com a EMBRAPA. Recebido para publicaçăo em 17 de janeiro e acelto em 6 de abril de 1990.

(2) Seção de Genética, Insttuto Agronómico (IAC), Caixa Postal 28, 13001 Campinas (SP).

(3) Seçăo de Microbiologia Fitotécnica, IAC.

(4) Estaçঝ̊ło Experimental de Pindorama, IAC.

(5) Estaçăo Experimental de Ribeiráo Preto, LAC.

(6) Sistema de Introduçăo e Quarentena de Plantas, IAC.

(7) Com bolsa de pesquisa do CNPq. 
resistente à verrugose e resistente à mancha-barrenta $\theta$ à ferrugem. Pela produtividade e nivel de resistência à doença, ambas estăo sendo incluldas em cruzamentos com linhagens de bom padrão comercial e qualidade de vagens, por suas limitaçðes para essas caracteristicas.

Termos de Indexaçấo: amendoim, germoplasma, potencial agronómico.

\section{ABSTRACT \\ AGRONOMIC POTENTIAL OF PEANUT GERMPLASM OF INTEREST TO BREEDING}

In order to select parental lines for the peanut (Arachis hypogaea L) breeding program, twenty three lines of the Instituto Agronormico peanut collection, as well as cultivars Tatuf and Tatu, were evaluated for pod yield, reactions to foliar diseases, seed oil content and other plant characters. The evaluations were carried out during the spring-summer growing seasons of 1985 and 1986 at the Centro Experimental de Campinas and Pindorama Experimental farm and, 1985, at the Ribeirăo Preto, Experimental farm, State of Săo Paulo, Brazil. Lines 5475, 5207, 5249 and $\mathrm{H}-69$, and the cultivar Tatuf significantly higher than the control (cv. Tatu). The best yields were observed in lines 5475 (an erect, short-cycle line of the Valencia group) and 5207 (a "bunch" type, long-cycle line of the Virginia group) which showed average yields $30 \%$ higher than the cultivar Tatu. Lines 269 and 70 were the only ones to present seed oil contents superior to the control, in $3 \%$. The good yielders, 5207 and 5249, presented oil contents significantiy lower than the control. Some of the lines showed to bear, in their genotypes, along with the yield potential, some level of resistance to the main foliar diseases. That was the case of line 5207 , rated as moderately suscetible to late leafspot and scab, and moderately resistant to web blotch, and line 5475, as moderately suscetible to late leafspot, moderately resistant to scab and resistant to web blotch and rust. For their yielding ability and levels of disease resistance, these lines have already been included in crosses with lines that have trait for good pod type and quality, as both present limitations on these characteristics.

Index terms: peanut, germplasm, agronomic potential.

\section{INTRODUÇÃO}

O amendoim (Arachis hypogaea, L.), no Estado de São Paulo, vem, desde o início da década de 70, sofrendo gradativa redução de área plantada $e$, conseqüentemente, de produçăo. Uma das principais causas é sua baixa rentabilidade em relação às outras culturas (INFORMAÇĀO SEMANAL CACEX, 1985). 
Um aumento do seu rendimento económico, na fase agrícola, poderia ser alcançado através da utilização de cultivares mais produtivos. Assim, a obtenção de cultivares de elevada capacidade produtiva, através do melhoramento genético, tem sido um dos pontos prioritários de suas pesquisas no Instituto Agronômico (SĀO PAULO, 1985).

A média de produtividade do amendoim em casca no Estado de São Paulo, para a cultura das águas, tem girado em torno de $1.800 \mathrm{~kg} / \mathrm{ha}$, com o cultivar Tatu, predominante nas regiōes produtoras (LASCA, 1984). Resultados mais recentes demonstram que um incremento de produtividade da ordem de 15-20\% pode ser obtido pela seleção de linhagens a partir de cruzamentos envolvendo cultivares locais dos grupos Valência e Spanish (POMPEU et al., 1986), o que elevaria a média do Estado para $2.000-2.200 \mathrm{~kg} / \mathrm{ha}$, nos mesmos padrões tecnológicos.

A obtenção de cultivares de elevada capacidade produtiva foi, em grande parte, o fator responsável pela elevação da produtividade da cultura nos Estados Unidos, cuja média atual é superior a $3.000 \mathrm{~kg} / \mathrm{ha}$ (HAMMONS, 1980). Considerando-se que esse patamar foi atingido através da exploração de ampla variabilidade genética (incluindo germoplasma do grupo Virgínia, ainda pouco explorado em nossas condições), pode-se, teoricamente, prever ganhos de seleção capazes de elevar a média de São Paulo acima de $2.200 \mathrm{~kg} / \mathrm{ha}$.

O melhoramento genético do amendoim visando ao aumento da capacidade produtiva aos niveis propostos requer a seleção a partir de hibridação artificial entre parentais previamente escolhidos. As chances de obtenção de segregantes de elevada capacidade produtiva são maiores quando os parentais envolvidos nos cruzamentos apresentam, no mínimo, o mesmo nivel de produtividade dos cultivares atuais. Assim, a escolha dos parentais para os cruzamentos, através da avaliação de um número apreciável de linhagens e cultivares introduzidos, é uma etapa inicial importante para o programa de melhoramento (NORDEN et al., 1982).

O teor de óleo nas sementes é um caráter a ser considerado no amendoim produzido em nossas condiçōes, uma vez que a maior parte da produçāo brasileira é destinada à extração de óleo. Embora o nosso amendoim comercial possua um teor de óleo satisfatório, a inclusão de germoplasma geneticamente mais diversificado ao programa poderia significar a introdução de genótipos com teor de óleo menor do que o padrão comercial (GODOY et al., 1989). Assim, o caráter deve ser pelo menos "monitorado", quando da avaliação do germoplasma disponivel para os cruzamentos ou das linhagens nas geraçōes avançadas de seleçāo.

A utilização de cultivares resistentes às principais doenças fúngicas foliares do amendoim, em especial as cercosporioses, é outro item concorrente para a elevação do rendimento econômico da cultura, pela conseqüente diminuição dos custos, resultante da redução de aplicaçōes de defensivos. A seleção 
para a resistência, como caráter primário, envolve a utilização de genótipos de reduzida capacidade produtiva, além de outros caracteres indesejáveis (GODOY \& MORAES, 1987), demandando um programa de cruzamentos e seleção à parte. Todavia, alguma resistência, mesmo em niveis moderados, pode ser encontrada entre genótipos agronomicamente aceitáveis, como foi observado por MORAES \& GODOY (1985a) com relaçāo ao Cercospcridium personatum.

Visando à identificaçāo dos melhores parentais para o programa de melhoramento, acessos introduzidos à coleção de germoplasma vêm sendo indicados, após sua observação quando ainda em coleção, para compor ensaios de competição onde são avaliados o nivel de produtividade, teor de óleo, resistência a doenças e outros caracteres agronômicos de interesse.

O presente trabalho mostra o desempenho médio de 24 desses acessos, entre linhagens e cultivares, em cinco ensaios implantados em 1985/86 e 1986/87, bem como uma discussão sobre o seu potencial para o programa.

\section{MATERIAL E MÉTODOS}

Vinte e quatro acessos, linhagens e cultivares de amendoim de diversas procedências (Quadro 1), foram incluidos em ensaios de campo com delineamento em blocos ao acaso com quatro repetiçōes, durante o ciclo das águas de 1985/86 e 1986/87 no Centro Experimental de Campinas e na Estação Experimental de Pindorama, e em 1985/86 na Estação Experimental de Ribeirão Preto. Os ensaios incluíram, ainda, o cultivar Tatu, usado como controle, totalizando 25 tratamentos.

Cinco dos tratamentos relacionados - 70, 267, 269, 5207 e 5249 - são classificados como do grupo Virgínia (subespécie hypogaea). Os demais apresentam características típicas dos grupos Spanish e Valência (subespédie fastigiata).

Quando da instalação de cada ensaio, efetuaram-se calagem e adubação padronizadas com base nas recomendações médias para o Estado de São Paulo. $\mathrm{Na}$ calagem, aplicaram-se, a lanço três meses antes do plantio, 2t/ha de calcário dolomítico. A adubação, realizada no sulco de plantio, consistiu em $350 \mathrm{~kg} / \mathrm{ha}$ da fórmula 4-14-8.

Cada parcela consistiu em uma linha de $5 \mathrm{~m}$, espaçada de $0,70 \mathrm{~m}$ das demais. Utilizaram-se, na semeadura, 75 sementes por linha, efetuando-se um desbaste, aos vinte dias do plantio, para permitir um estande de 50 plantas/linha. Durante o ciclo, realizaram-se pulverizações periódicas com inseticida à base de dimetoato, para o controle de tripes, e fungicidas à base de clorotalonil, para o da cercosporiose.

Avaliou-se a produção em casca nos cinco experimentos e o teor de óleo nas sementes, em quatro deles, como caracteres primários, tendo em vista o seu interesse para o programa de melhoramento. A produção em casca foi obtida 
após a colheita de cada parcela e secagem das vagens ao sol, em terreiro. Determinou-se o teor de óleo nas sementes pelo método de ressonância magnética nuclear (RNM), com base na média de leiturà de três amostras de sementes retiradas ao acaso de cada parcela. Os dados foram analisados estatisticamente $\theta$ as médias de cada tratamento (por experimento e no conjunto deles, comparadas com a do controle, cultivar Tatu, pelo teste de Dunnett a 5\% (STEEL \& TORRIE, 1960).

QUADRO 1. Procedência das linhagens e cultivares introduzidos à coleção de germoplasma e avaliados nos ensaios de 1985/86 e 1986/87

Linhagem/ Origem ou procedência
Cultivar

\begin{tabular}{|c|c|}
\hline $\begin{array}{r}3 \\
70\end{array}$ & $\begin{array}{l}\text { Introduzida do Rio Grande do Sul, com a denominaçáo de "amendoim-1". } \\
\text { Introduzida da regiăo produtora do Estado de Săo Paulo, munícipio de Penápo- } \\
\text { lis, sem denominação. }\end{array}$ \\
\hline 267 & Introduzida da Carolina do Norte (EUA) com a denominaçăo de "C-37". \\
\hline 269 & Introduzida da Carolina do Norte (EUA) com a denominaçăo de "C-42". \\
\hline 499 & Introduzida da Argentina, sem denominaçăo. \\
\hline 521 & Introduzida da Argentina, com a denominação de cultivar Natal. \\
\hline 535 & Introduzida da Argentina, sem denominaçăo. \\
\hline 684 & Linhagem avançada do Melhoramento, introduzida da Argentina. \\
\hline 902 & Introduzida da Flórida (EUA), denominada PI 337409. \\
\hline 925 & Introduzida da Nigéria, denominada 55-437. \\
\hline 1034 & Seleção do IAC, do cruzamento da linhagem 405 com o cultivar Tatuf. \\
\hline 2199 & Introduzida da regiăo produtora de Săo Paulo, sem denominaçăo. \\
\hline 5207 & Linhagem componente do cultivar multilinha Altika, desenvolvido na Flórida (EL \\
\hline $\begin{array}{l}5249 \\
5475\end{array}$ & $\begin{array}{l}\text { Linhagem avançada do Melhoramento, introduzida da Flórida (EUA). } \\
\text { Introduzida da Geórgia (EUA) sob a denominaçáo de "Tifrust-14", liberado } \\
\text { como germoplasma resistente à ferrugem. }\end{array}$ \\
\hline 5565 & Introduzida da regiăo produtora de Săo Paulo, com a denominaçăo de "J-120". \\
\hline 5567 & $\begin{array}{l}\text { Introduzida da região produtora de São Paulo, municlpio de Herculândia, sem } \\
\text { denominaçăa. }\end{array}$ \\
\hline $\begin{array}{l}5569 \\
\text { Ca-34 }\end{array}$ & $\begin{array}{l}\text { Introduzida da regiăo produtora de Săo Paulo, sem denominaçăo. } \\
\text { Linhagem selecionada do cultivar Tatu, no Instituto Agronómico. }\end{array}$ \\
\hline $\mathrm{H}-69$ & Seleção do IAC, do cruzamento da linhagem 399 com o cultivar Tatu. \\
\hline Roxo 80-1 & Linhagem selecionada do cultivar Roxo, no Instituto Agronômico. \\
\hline Ti-V & $\begin{array}{l}\text { Introduzida da regiáo produtora de Săo Paulo.com a denominaçăo de cultivar } \\
\text { Tatú Vermelho. }\end{array}$ \\
\hline Tatul & Cultivar produzido em pequena escala no Estado de Săo Paulo. \\
\hline TBM & $\begin{array}{l}\text { Introduzida da regiăo produtora de Săo Paulo, municlpio de Rosália, com a } \\
\text { denominaçăo de cultivar Tatu Branco. }\end{array}$ \\
\hline Tatu & Cultivar produzido em larga escala no Estado de Săo Paulo. \\
\hline
\end{tabular}


Como o controle proporcionado pelas pulverizaçōes com clorotalonil foi parcial, houve possibilidade de avaliar as reaçōes de cada linhagem e cultivar a quatro das principais doenças do amendoim em um ou mais experimentos, quando da ocorrência dos patógenos. A pinta-preta (Cercosporidium personatum) foi avaliada em Campinas em 1985/86 e 1986/87, e em Pindorama, em 1985/86; a ferrugem (Puccinia arachidis) e a mancha-barrenta (Phoma arachidicola), em Campinas, em ambos os anos, e a verrugose (Sphaceloma arachidis) em Campinas em 1985/86.

Atribuíram-se, a cada genótipo e para cada doença, notas visuais da reação média observada em comparação com o cultivar Tatu, o padrão suscetível, segundo escala de reaçōes (variando de suscetivel a resistente) utilizada por MORAES et al. (1983) e MORAES \& GODOY (1985b). Esta escala se baseia para as quatro doenças, no índice de infecção (\%), enquanto, para pinta-preta e ferrugem, o grau de esporulação das lesōes também é considerado, conforme se segue:

$S$ - suscetível: com folíolos apresentando indices de infecção (porcentagem da área infectada em relaçāo à área do folíolo) superiores a $50 \%$ do índice de infecção observado no padrão suscetivel; lesōes típicas e esporulação abundante.

MS - moderadamente suscetivel: índices de infecção entre 25 e $50 \%$ em relação ao padrão suscetivel; lesões típicas, porém com tamanho reduzido e esporulação moderada.

$M R$ - moderadamente resistente: índices de infecção entre 10 e $25 \%$ em relação ao padrão suscetivel; lesões típicas de tamanho reduzido e esporulação rara.

$R$ - resistente: índices de infecção inferiores a $10 \%$ em relação ao padrão suscetível; lesões atípicas, com esporulaçāo rara ou ausente.

Em cada linhagem ou cultivar, anotaram-se, ainda, os seguintes caracteres: 9 = rasteiro).

Porte de planta: segundo escala de notas visuais de 1 a $9(1=$ ereto;

Ciclo: número de dias, do plantio à maturação fisiológica.

Reticulaçáo de vagem: segundo escala de notas visuais de 1 a 7 ( 1 = superfície externa lisa; 7 = profundamente reticulada).

Constrição de vagem: presença e/ou intensidade da "cintura", conforme escala de notas visuais de 1 a 9 ( 1 = ausência de constrição; $9=$ constrição muito profunda).

Aparência de vagens: levando-se em consideração a uniformidade na amostra, o formato e a coloração externa, de acordo com escala de notas visuais de 1 a 9 ( 1 = má; 9 = muito boa). 
Rendimento de sementes: peso das sementes/peso do amendoim em casca $\times 100$, onde $1=60-65 \%, 2=70 \%$ e $3=$ acima de $70 \%$.

Número de sementes por vagem: número médio encontrado na maioria das vagens da amostra. tradas ao acaso.

Peso médio de sementes: peso, em gramas, de cem sementes amos-

Cor da película da semente: $\mathrm{Cr}=$ creme; $\mathrm{R}=$ rósea; $\mathrm{Ve}=$ vermelha.

\section{RESULTADOS E DISCUSSÃO}

As produçōes médias, em casca, das linhagens e cultivares de amendoim avaliados em cinco experimentos, encontram-se no quadro 2.

O teste de Dunnett, aplicado ao nivel de $5 \%$ para comparação das médias de cada tratamento com a do 'Tatu', usado como controle, não acusou diferenças significativas entre este e os tratamentos com as maiores produçōes em Campinas, 1985/86. Com exceção das linhagens 521 e 5569, cujas médias foram significativamente inferiores à do controle, as demais estiveram na mesma amplitude de variação da médla do controle, de $3.915 \mathrm{~kg} / \mathrm{ha}$. Sobressaíram-se, todavia, com médias próximas da significância, as linhagens 5475 e 5207, com 4.686 e $4.718 \mathrm{~kg} / \mathrm{ha}$ respectivamente. Na mesma localidade, em 1986/87, nenhum dos tratamentos diferiu estatisticamente do controle, cuja média de produção foi de $2.754 \mathrm{~kg} / \mathrm{ha}$.

Em Pindorama, 1985/86, as linhagens 5475, 5207 e 5567 apresentaram produçōes significativamente superiores $(4.778,4.071$ e $4.000 \mathrm{~kg} / \mathrm{ha}$ respectivamente) à do cultivar Tatu, que produziu $3.028 \mathrm{~kg} / \mathrm{ha}$. Em 1986/87, no experimento de maior média de produção $(4.571 \mathrm{~kg} / \mathrm{ha})$, onde o controle produziu $4.250 \mathrm{~kg} / \mathrm{ha}$, destacaram-se estatisticamente as linhagens $5475,5207,5249$ e H-69 e os cultivares Tatui e Tatui Vermelho (Ti-V), com médias superiores a $5.000 \mathrm{~kg} / \mathrm{ha}$. A linhagem 5475 atingiu $6.143 \mathrm{~kg} / \mathrm{ha}$.

Em Ribeiräo Preto, 1985/86, cuja média do ensaio foi de $4.209 \mathrm{~kg} / \mathrm{ha}$, as linhagens 5207, 5249. e Roxo 80-1 produziram, respectivamente, 5.262, 5.157 e $4.740 \mathrm{~kg} / \mathrm{ha}$, médias significativamente superiores à do controle, $3.753 \mathrm{~kg} / \mathrm{ha}$.

$\mathrm{Na}$ média dos cinco experimentos, cinco tratamentos se destacaram: $5475,5207,5249, \mathrm{H}-69$ e 'Tatui', cujas produçōes variaram de 4.065 a $4.606 \mathrm{~kg} / \mathrm{ha}$, significativamente superiores, pelo teste de Dunnett, à média geral do controle, $3.540 \mathrm{~kg} / \mathrm{ha}$.

O quadro 3 mostra os teores médios de óleo nas sementes das linhagens e cultivares em quatro experimentos envolvendo três localidades, nos anos agrícolas de 1985/86 e 1986/87.

Contirmando observações anteriores (GODOY et al., 1989), as sementes do cultivar Tatu mostraram possuir um teor de óleo que se situa na parte superior da amplitude que tem sido observada no germoplasma estudado até o momento. 


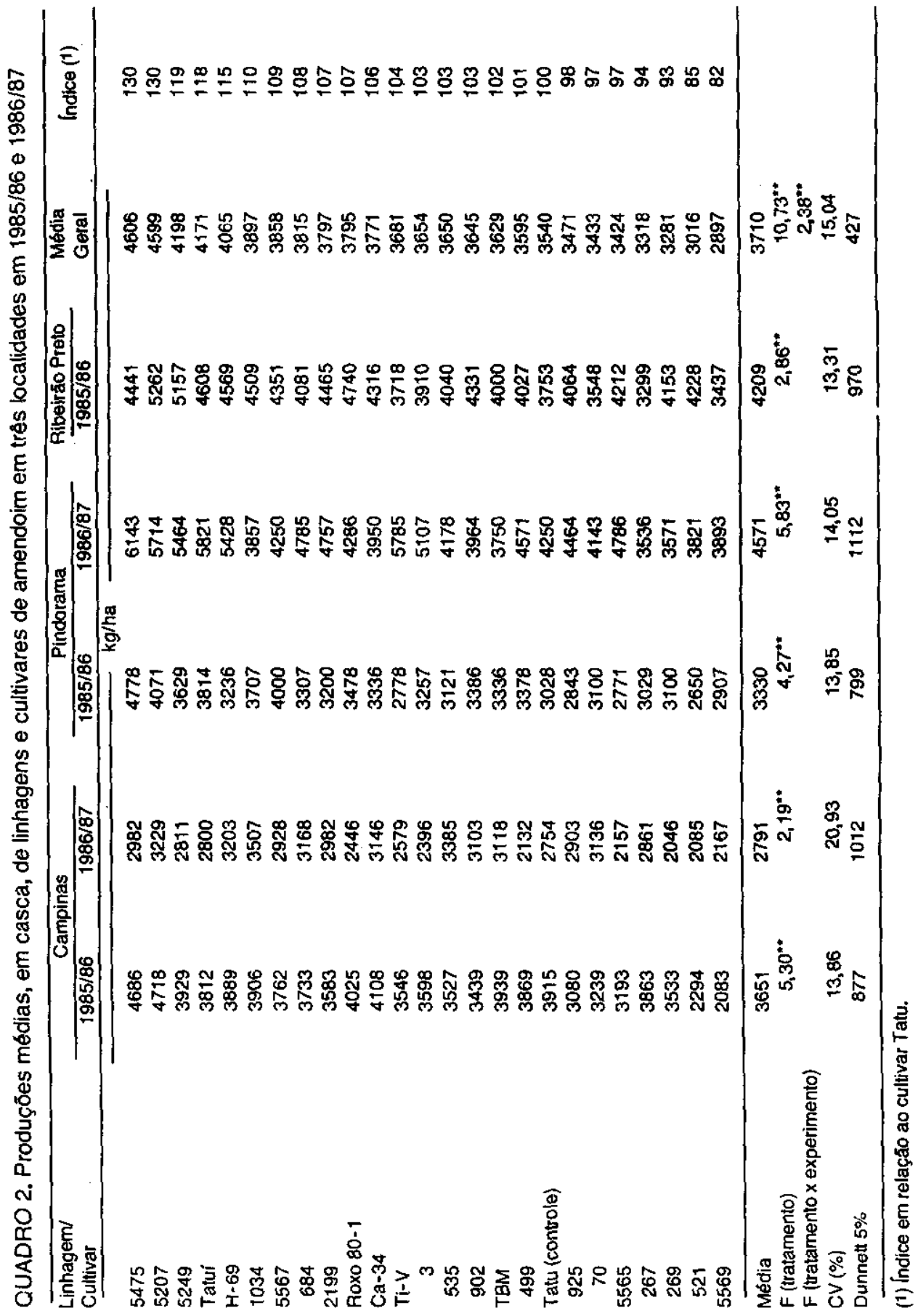




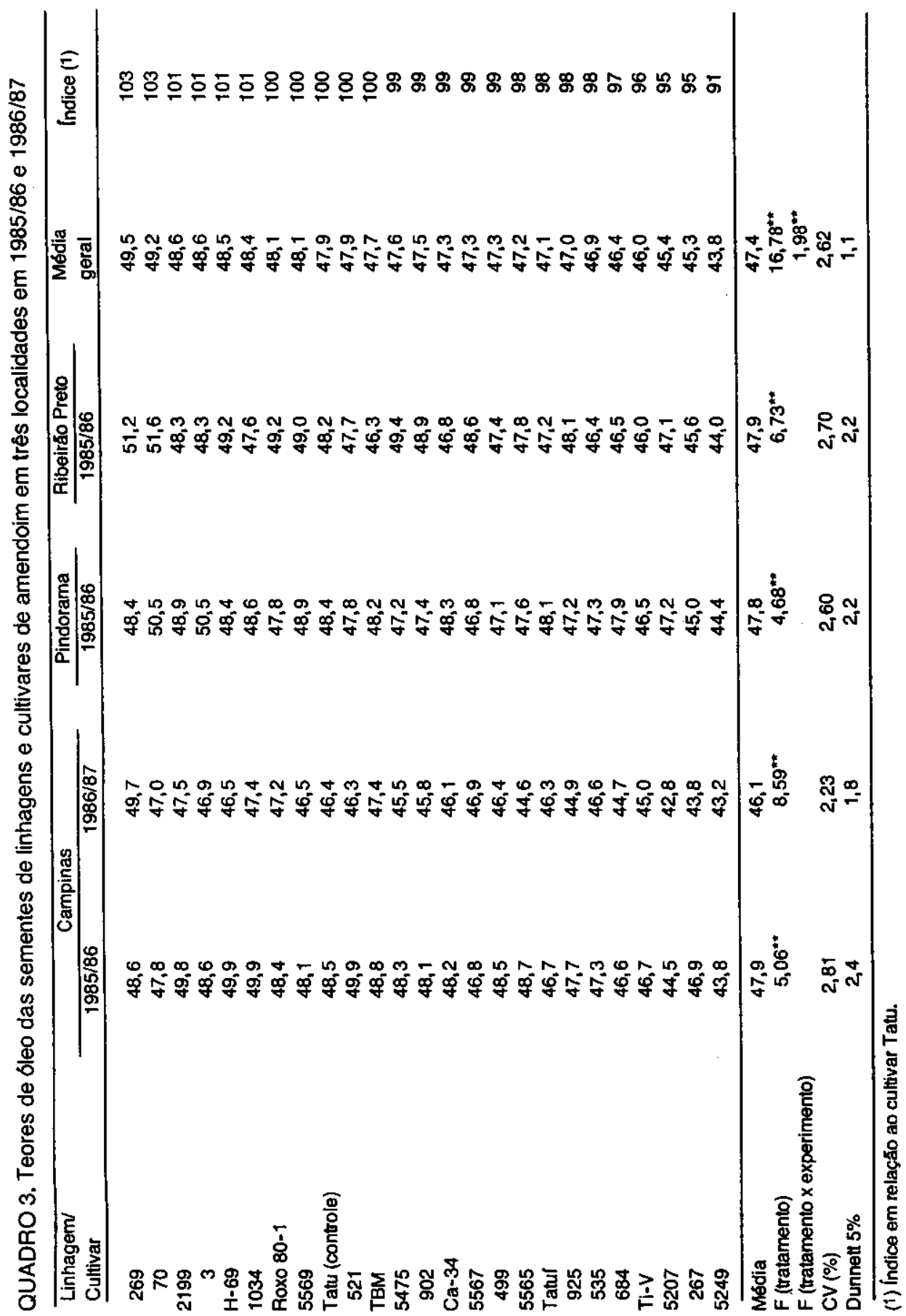


Entre as linhagens e cultivares avaliados neste trabalho, a 269 e a 70 foram as únicas a exibir teores de óleo significativamente maiores que os do controle, em alguns experimentos. Em Ribeirão Preto, a 269 apresentou 51,2 e a 70, $51,6 \%$, contra $48,2 \%$ do 'Tatu'. Em Campinas, 1986/87, a 269, com 48,7\%, foi significativamente superior ao controle, 46,4\%. As duas linhagens, a 269 com 49,5 e a 70 com $49,2 \%$ foram significativamente superiores ao controle na média dos quatro experimentos.

Ainda na média geral, as linhagens $267,684,5207$ e 5249 e o cv. Tatui Vermelho, apresentaram teores de óleo significativamente menores que o do controle, com índices que variaram de 91 a 97 em relação ao índice $100 \mathrm{do} \mathrm{cv}$. Tatu.

As reaçōes médias das linhagens e cultivares a quatro das manchas fúngicas foliares observadas nos experimentos, em comparação com o controle, encontram-se no quadro 4.

QUADRO 4. Reações de linhagens e cultivares de amendoim a doenças da parte aérea (1)

\begin{tabular}{|c|c|c|c|c|}
\hline \multirow{2}{*}{$\begin{array}{l}\text { Linhagem/ } \\
\text { Cultivar }\end{array}$} & \multicolumn{4}{|c|}{ Doenças } \\
\hline & Pinta-preta & Verrugose & Ferrugem & Mancha-bartenta \\
\hline 3 & $\mathrm{~s}$ & MS & $\mathrm{s}$ & MS \\
\hline 70 & MR & R-MR & MS & $R$ \\
\hline 267 & MS & MR & $\mathrm{s}$ & $R$ \\
\hline 269 & MS & MS-S & MS-S & $\mathbf{R}$ \\
\hline 499 & S & MS & MS & $\mathbf{S}$ \\
\hline 521 & $S$ & $\mathrm{~s}$ & MS-S & $\mathrm{S}$ \\
\hline 535 & $\mathbf{S}$ & MR & MS-S & $S$ \\
\hline 684 & $S$ & MS & $s$ & $S$ \\
\hline 902 & $S$ & MS & MS & MS-S \\
\hline 925 & $\mathbf{S}$ & $\mathrm{S}$ & $s$ & $\mathrm{~S}$ \\
\hline 1034 & $S$ & MS & $S$ & MS \\
\hline 2199 & $S$ & $s$ & $\mathbf{S}$ & $\mathrm{s}$ \\
\hline 5207 & MS & MR-MS & $\mathrm{S}$ & R-MP \\
\hline 5249 & MS-S & $s$ & MS-S & R \\
\hline 5475 & MS & MR & $\mathrm{R}$ & $\mathrm{R}$ \\
\hline 5565 & $s$ & MS-S & $S$ & $\mathrm{~S}$ \\
\hline 5567 & MS-S & $\mathrm{S}$ & MS-S & MR \\
\hline 5569 & $S$ & $\mathrm{~S}$ & $\mathrm{~S}$ & $\mathbf{s}$ \\
\hline $\mathrm{Ca}-34$ & $S$ & $\mathrm{~S}$ & MS-S & $R-M R$ \\
\hline $\mathrm{H}-69$ & $\mathrm{~s}$ & MS-S & $S$ & MS-S \\
\hline Roxo 80-1 & MS-S & MS-S & MS-S & $S$ \\
\hline $\mathrm{Ti}-\mathrm{V}$ & $S$ & $s$ & $\mathrm{~S}$ & $S$ \\
\hline Tatui & $\mathrm{s}$ & MS.S & $\mathrm{S}$ & MS \\
\hline TBM & $\mathrm{S}$ & $s$ & $S$ & $s$ \\
\hline Tatu & $\mathrm{s}$ & $\mathrm{s}$ & $s$ & $\mathrm{~s}$ \\
\hline
\end{tabular}

(1) Reaçōes médias segundo escala de notas visuais: $S=$ suscetfvel; MS-S = moderadamente suscetivel a suscetfvel; $M S=$ moderadamente suscetivel; $\quad M R-M S=$ moderadamente resistente a moderadamente suscetivel; $\quad M R=$ moderadamente resistente; $R-M R=$ resistente a moderadamente resistente; $\quad R=$ resistente. 
Com relação à pinta-preta (Cercosporidium personatum), a doença de maior freqüência e danos nas condiçöes paulistas, algumas das linhagens apresentaram reaçōes diferenciadas do cultivar Tatu, suscetivel. Destacaram-se as linhagens 70 , como moderadamente resistente, e a $267,269,5207$ e 5475, como moderadamente suscetiveis.

Das reações anotadas para verrugose (Sphaceloma arachidis), a segunda doença de importância em nossas condiçōes, a linhagem 70 foi classificada como resistente a moderadamente resistente. Com reações de moderada resistência, sobressaíram 267, 535 e 5475.

A linhagem 5475, germoplasma considerado como fonte de resistência à ferrugem (Puccinia arachidis), confirmou-a. As linhagens 70, 499 e 902 apresentaram reaçōes de moderada suscetibilidade.

Vários tratamentos mostraram reaçōes de resistência à mancha-barrenta (Phoma arachidicola) em diversos niveis, destacando-se como resistentes as linhagens $70,267,269,5249$ e 5475. A 5567 foi classificada como moderadamente resistente, e a 5207 e Ca-34 como resistentes a moderadamente resistentes.

Observações anteriores confirmam as reaçōes de resistência das linhagens 70 e 269, bem como a suscetibilidade da Roxo 80-1 e dos cultivares Tatui e Tatu Branco (MORAES et al., 1983, 1988 ; MORAES \& GODOY, 1985a,b).

No quadro 5 encontram-se as características varietais das linhagens $\mathrm{e}$ cultivares avaliados.

Com base no desempenho produtivo, no teor de óleo das sementes, nas reaçōes a doenças e nos principais atributos relativos às vagens e sementes, é de interesse uma discussão sobre as possibilidades do material estudado para os trabalhos de melhoramento genético.

Como material parental para os cruzamentos visando à seleção para produção de vagens, destacaram-se, além do cultivar Tatuí, as linhagens 5475, 5207,5249 e $\mathrm{H}-69$, que apresentaram produtividade significativamente superior à do controle. A utilização desses genótipos aumentaria as chances de obtenção de segregantes de elevado potencial produtivo, desconsiderando-se as outras características.

Seleçōes a partir de cruzamentos envolvendo as linhagens 269 e 70 poderiam proporcionar ganhos genéticos no rendimento em óleo, embora nenhum material avaliado tenha exibido superioridade marcante para essa característica. Em contrapartida, a utilização das linhagens 267, 684, 5207 e 5249, além do cv. Tatui Vermelho, como parentais, introduziriam genes para baixo teor de óleo nas sementes. A linhagem 5249, em especial, mostrou um rendimento em óleo $9 \%$. inferior ao controle.

A obtenção de cultivares produtivos do tipo Virginia, de hábito de crescimento rasteiro a arbustivo (de nota 5 a 8, na escala de porte de planta - Quadro 5) e ciclo entre 130 e 140 dias, é um dos objetivos do melhoramento. Plantas 


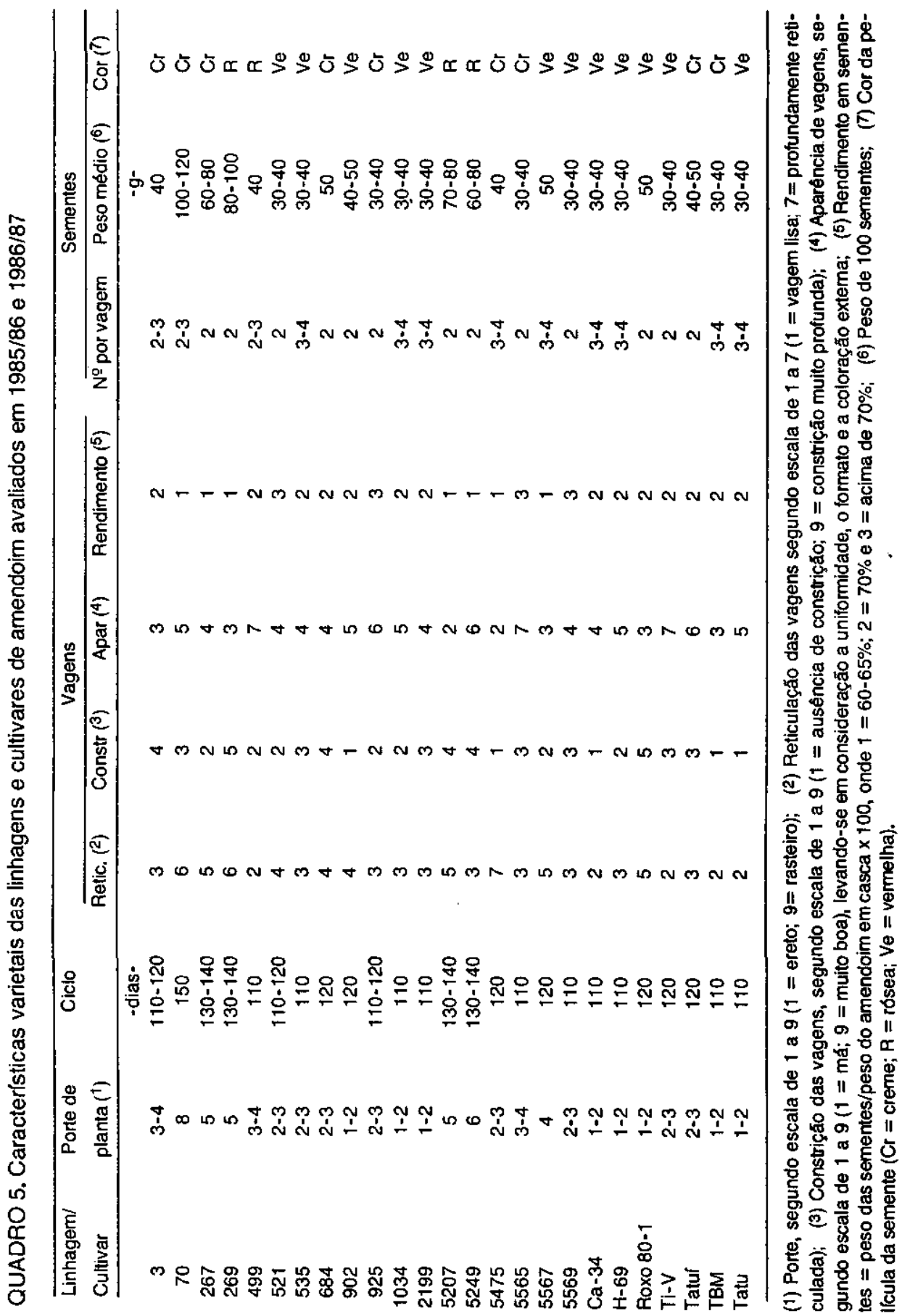


com essas caracteristicas vegetativas possuem como vantagem a possibilidade de colheita totalmente mecanizada. O ciclo mais longo permitiria a colheita fora do periodo mais chuvoso do ano.

Entre as linhagens do tipo Virgínia, a 70 apresenta, como principal atributo, a relativa resistência à pinta-preta e à verrugose e a elevada resistência à mancha-barrenta. Possui, entretanto, moderada capacidade produtiva, sementes de tamanho muito acima do padrão comercial e ciclo excessivamente longo.

Pelo seu potencial produtivo, e por serem portadoras de alguma resistência às manchas foliares, em especial à mancha-barrenta, as linhagens $5207 \mathrm{e}$ 5249 seriam as mais indicadas para o melhoramento visando à capacidade produtiva. Ambas, porém, mostram como limitaçōes caracteristicas indesejáveis de vagens, como a constrição pronunciada e o rendimento abaixo de $70 \%$. A 5207 apresenta má aparência de vagens (nota 2), devido à má conformaçăo e à tonalidade escura da casca. Ambas apresentam, ainda, como visto, teores de óleo abaixo do nivel do 'Tatu'.

Várias linhagens são opçōes para cruzamentos com a 5207 e 5249, pois oferecem complementaridade para as características de qualidade de vagens e teor de óleo. É o caso da 499, 925, 1034, 5565 e H-69 e dos cultivares Tatui e TiV. O 'Tatui e a linhagem $\mathrm{H}-69$ se destacaram pelos niveis de produtividade superiores ao do 'Tatu'.

Para a obtenção de segregantes do tipo ereto, precoce (padrão atual do nosso amendoim comercial), a linhagem 5475 possui excelente potencial. Além de uma capacidade produtiva significativamente superior à do controle comercial, foi avaliada como moderadamente suscetivel à pinta-preta, moderadamente resistente à verrugose e resistente à ferrugem e à mancha-barrenta. Apresenta como deficiências a profunda reticulação e a má aparência das vagens, e rendimento em sementes inferior ao do padrăo comercial. Assim, deve ser incluída em cruzamentos com aqueles parentais de bom desempenho produtivo e com as melhores características de vagens.

Seleções a partir de cruzamentos, simples e múltiplos, envolvendo os melhores parentais aqui descritos, encontram-se em andamento no programa de melhoramento do Instituto Agronómico.

\section{REFERÊNCIAS BIBLIOGRÁFICAS}

GODOY, I.J. \& MORAES, S.A. Herança da resistência a Cercosporidium personatum e correlação com caracteres agronómicos em cruzamentos intra-especfficos de amendoim. Fitopatologia Brasileira, Brasilia, 12(3):245-250, 1987.

; PEREIRA, J.C.V.N.A. \& MARTINS, A.L.M. Capacidade de produção de grăos e de óleo em linhagens e cultivares de amendoim. Bragantia, Campinas, 48(1):27-38, 1989. 
HAMMONS, R.O. Research and extension inputs resulting in high yields of groundnuts in the USA. In: INTERNATIONAL WORKSHOP ON GROUNDNUTS, Patancheru, 1980. Proceedings. Patancheru, ICRISAT, 1980. p.33-39.

INFORMAÇĀO SEMANAL CACEX. Rio de Janeiro, Banco do Brasil S.A., n.960, 1985.

LASCA, D.H.C. Amendoim: produção em Săo Paulo. A Granja, Porto Alegre, 40(443):74$-78,1984$.

MORAES, S.A. \& GODOY, I.J. Avaliação da resistência a Cercosporidium personatum em genotipos de Arachis hypogaea. Summa Phytopathologica, Jaboticabal, 11(3/4):140-151, 1985a.

\& - Diferentes niveis de resistência a Cercosporidium personatum em genotipos de Arachis hypogaea. Summa Phytopathologica, Jaboticabal, 11:(1/2):74-86, 1985b.

\& GERIN, M.A.N. Avaliaçăo da resistência de Arachis hypogaea a Puccinia arachidis, Sphaceloma arachidis e Phoma arachidicola. Fitopatologia Brasilei ra, Brasilia, 8(3):499-506, 1983.

; PEDRO JÚNIOR, M.J. \& PEREIRA, J.C.V.N.A. Epidemiologia de Cercosporidium personatum em genótipos de amendoim. Fitopatologia Brasileira, Brasilia, 13(3):255-260, 1988.

NORDEN, A.J.; SMITH, O.D. \& GORBET, D.W. Breeding of the cultivated peanut. In: PATTEE, H.E. \& YOUNG, C.T., eds. Peanut science . and technology. Yoakum, Texas, American Peanut Research and Education Society, 1982. p.95-122.

POMPEU, A.S.; GERIN, M.A.N.; PEREIRA, J.C.V.N.A.; BORTOLETTO, N.; YOKOYAMA, T.; HOJO, S. \& NAGAI, G.M. Estimativa da capacidade produtiva de novas linhagens de amendoim (Arachis hypogaea L.) no Estado de São Paulo. Ciência e Cultura, Săo Paulo, 38(6):1075-1080, 1986.

SĀO PAULO. Secretaria de Agricultura e Abastecimento. Coordenadoria da Pesquisa Agropecuária. Programa Integrado de Pesquisa: oleaginosas, por I.J. de Godoy, A. Savy Filho, J.S. Tango, R.M.G. Úngaro \& P.R. Mariotto. SãoPaulo, 1985. 33p.

STEEL, R.G.D. \& TORRIE, J.H. Analysis of variance. I: the one-way classification. In: - \& - Principles and procedures of statistics. New York, McGraw-Hill, 1960. p.99-131. 